\title{
Geographic variation in hospital costs, payments, and length of stay for opioid-related hospital visits in the USA
} This article was published in the following Dove Press journal:
Journal of Pain Research

\section{Peter J Mallow' \\ Kathy W Belk² \\ Michael Topmiller ${ }^{3}$ \\ Scott A Strassels ${ }^{4}$}

'Health Services Administration, Xavier University, Cincinnati, $\mathrm{OH}$ 45229, USA; ${ }^{2}$ Health Data Analytics, Vizient, Inc., Mooresville, NC 28I I 5 , USA; ${ }^{3}$ HealthLandscape, American Academy of Family Physicians, Cincinnati, OH 45209, USA; ${ }^{4}$ Department of Surgery, Center for Surgical Health Assessment, Research, and Policy, Ohio State University,

Columbus, $\mathrm{OH} 43210$, USA
Correspondence: Peter J Mallow Health Services Administration, Xavier University, 3800 Victory Parkway,

Cincinnati, OH 45229, USA

$\mathrm{Tel}+\mathrm{I} 5 \mathrm{I} 37453636$

Email mallowp@xavier.edu
Purpose: Despite the rise in opioid-related hospitalizations, there has been little research regarding opioid-related healthcare utilization. The objective of this study was to estimate the mean adjusted hospital costs, payments, and length of stay (LOS) for opioid-related visits for the nation and each of the nine US census regions.

Methods: An observational study of retrospective claims data from the Vizient health system database was conducted. Eligible visits had a principal diagnosis of opioid use or dependence defined by ICD, ninth and tenth revision (ICD-9/10), and occurred between January 2014 and June 2017. Separate regression models for inpatient and outpatient visits were generated to estimate the adjusted costs, payments, and LOS for opioid-related visits.

Results: A total of 193,614 (32,713 inpatient and 160,901 outpatient) visits met the inclusion criteria. The overall adjusted mean cost, payment, and LOS for an inpatient opioid-related visit were $\$ 4,383$ (range between regions: $\$ 2,894-\$ 5,835$ ), $\$ 6,689$ (range between regions: $\$ 4,038-\$ 9,001$ ), and 4.35 days (range between regions: 3.8-5.7 days), respectively. The overall adjusted mean cost and payment for an outpatient opioid-related visit were $\$ 533$ (range between regions: \$395-\$802) and \$374 (range between regions: \$187-\$574), respectively. Opioid-related hospital costs, payments, and LOS varied across the US. Data on the regional variation and national averages are necessary for hospitals to benchmark their services and more effectively manage this population.

Conclusion: Future research should examine intraregion utilization to understand the effect of prices and level of services.

Keywords: opioid use disorder, healthcare utilization, geographic variation, administrative claims

\section{Introduction}

The economic burden of the opioid crisis has been well documented with recent annual estimates exceeding $\$ 100$ billion and 53,000 deaths. ${ }^{1-4}$ Acute care hospitals are often on the frontline of the opioid crisis, and with the passage of the Affordable Care Act of 2010, hospitals are taking a more proactive approach to manage this population. ${ }^{5}$ Overdose victims arrive often through the emergency department (ED), and the hospital becomes the initial treatment center. ${ }^{6,7}$ Overall, the rate of opioid-related inpatient stays and ED visits has increased, 76\% and $117 \%$, respectively, from 2005 to $2014 .{ }^{8}$ The magnitude of increase in opioid-related visits has been shown to vary widely based on patient location. ${ }^{9}$ Small metropolitan areas have seen an even larger increase $(121 \%)$ in inpatient stays and ED visits over this same time period.

A wide geographic variation in opioid-related deaths and visits has been documented previously. ${ }^{4-12}$ In 2015, the Northeast and Midwest regions had heroin overdose death rates about twice as high as the South and nearly three times as high as the West after controlling for population. ${ }^{4}$ For instance, Arkansas and Iowa consistently rank 
among the lowest for ED opioid-related visits, and Iowa, Nebraska, Texas, and Wyoming rank among the lowest for opioid-related inpatient visits. ${ }^{12}$ On the other hand, Connecticut and Massachusetts in the Northeast and Maryland in the Mid-Atlantic regions consistently rank among the highest in both inpatient and emergency opioid-related visits. ${ }^{12}$ There was almost a sixfold difference in opioid-related inpatient stays between the state with the fewest (Iowa, 72.7 stays per 100,000) and the highest (Maryland, 403.8 stays per 100,000). ${ }^{12}$ Likewise, ED visits varied nearly 10 -fold (Iowa, 45.1 visits per 100,000 and Massachusetts, 450.2 visits per 100,000) across states. ${ }^{12}$

One may expect to find similar geographic variation in hospital spending associated with opioid-related visits (cost and payment). Numerous studies have documented variation in pricing and services across the US. ${ }^{13-19}$ These studies have found that differences in pricing and utilization drive geographic variation after adjusting for patient demographics and hospital characteristics. The most recent estimates suggest that the typical hospital will lose $\$ 82$ per discharge across all clinical services. ${ }^{17}$ However, these estimates vary by geography with estimated loss of $\$ 236$ per patient in the Northeast to a profit of $\$ 45$ per visit in the West. ${ }^{17}$ There is a lack of objective and recent data quantifying the scope of the opioid epidemic within the hospital including associated costs, payments, and length of stay (LOS). ${ }^{18}$ This knowledge gap prevents hospitals from effective benchmarking and hinders performance improvements addressing the opioid crisis. The objective of this study was to estimate the mean adjusted hospital costs, payments, and LOS for opioid-related visits at both a national and regional level.

\section{Materials and methods Data source}

The Vizient health system data include inpatient and hospital-based outpatient administrative claim and detailed billing data across all payers for more than 400 acute care hospitals. ${ }^{20}$ The claims data include the principal diagnosis and all reported secondary diagnoses on the claim. Data are updated twice a month with a 30-45-day lag from month end and include more than 50 million visits annually. Hospitals in the Vizient health system data represent 41 states across USA and include a mix of urban and rural, large and small, and teaching and nonteaching facilities. These hospitals are primarily located in urban areas with bed sizes ranging from 16 to 2,391 (median 215). Ambulatory surgery centers and freestanding outpatient clinics are not included. These data are generally representative of the US hospital population as hospitals are predominately small to midsize, nonteaching facilities located in an urban setting.

All data used in this study were deidentified in conformance with the requirements of the Health Insurance Portability and Accountability Act (HIPAA). The institutional review board of the Xavier University exempted this study from review.

\section{Patient visit identification}

Any inpatient or outpatient visit with a principal diagnosis code related to opioid addiction, abuse, misuse, or dependence occurring between January 1, 2014, and June 30, 2017 , was eligible for study inclusion. Opioid-related visits were identified using ICD, ninth and tenth revision (ICD-9/10), diagnosis codes: 304.0x, 304.7x, 305.5x, 965.0x, F11.x, and T40.0x to T40.3x. This broad definition includes both prescription and nonprescription abuse of opioids, including heroin, carfentanil, and fentanyl. This definition is intentionally broad due to the various definitions of opioid-related visits reported in the literature and is considered a better capture of true opioid-related visits compared to the reliance on secondary diagnosis codes. ${ }^{21-24}$ To be included in the study, a patient was required to be greater than 1 year old at the time of admission and had a principal diagnosis code noted previously. This composite definition is referred to as "opioid-related visit" in this study.

\section{Statistical analyses}

Primary outcomes of interest were visit-related costs, payments, and, for inpatient admissions, LOS. Visit costs were calculated using hospital-specific cost-to-charge ratios. All data were stratified by the nine US census regions: East North Central, East South Central, Mid-Atlantic, Mountain, New England, Pacific, South Atlantic, West North Central, and West South Central as well as by inpatient vs outpatient setting. Patient and hospital characteristics were summarized with percentages for categorical data and mean and SD for continuous data. Outcome data were summarized with mean, median, and SD.

Generalized linear regression models (GLMs) with a gamma distribution and log link were used to estimate the mean cost, payment, and LOS of opioid-related visits by the US census region. The models were constructed separately for inpatient and outpatient visits. Results were reported for the nine regions and overall USA and included the 95\% CI of the adjusted estimate. A stepwise regression approach was used to include statistically significant patient and hospital characteristics. A $P$-value of 0.01 was used to identify statistically significant covariates due to the large sample size. 
Covariates included in the models were age, sex, Charlson Comorbidity Index (CCI), insurance provider, hospital bed size, teaching status, urban status, and ownership status. Discharge year was included in the model to control for changes in cost and payment over time. In addition, the following comorbidities associated with opioid use were included as model covariates: alcohol disorders, anxiety disorders, bipolar disorder, depression, hepatitis (acute and chronic), and the history of substance abuse. The CCI score was calculated using secondary diagnosis codes present on the claim as well as any previous diagnoses for that patient. All analyses were performed using SPSS v24 (IBM Corporation, Armonk, NY, USA).

\section{Results}

A total of 193,614 opioid-related visits were identified between January 1, 2014, and June 30, 2017: outpatient visits, 160,901; greatly outnumbered inpatient visits, 32,713 (Figure 1). The female outpatient population ranged from a low of $42 \%$ in the New England region to a high of $60 \%$ in the East South Central and West North Central regions (Table 1). In the inpatient setting, the female population ranged from a low of $38 \%$ in New England to a high of 58\% in the West North Central region. The average age was about 40 years with a range of 36.5 years (East North Central outpatient) to 48.6 years (West North Central inpatient). Generally, the patients were discharged to home; however, discharge status was unknown or missing for a significant number of visits. Inpatient visits were much more likely to leave against medical advice (range: $3 \%$, West North Central, to
$15 \%$, Mid-Atlantic). Payer information was largely unknown except in the Mid-Atlantic region, where Medicaid was the predominant payer comprising $49 \%$ of outpatient visits and $34 \%$ of inpatient visits.

The CCI, a measure of severity of illness, indicated that patients were healthier in the hospital outpatient department compared to those who were admitted. ${ }^{25}$ The mean CCI for outpatient visits ranged from 0.4 in the East North Central region to 0.8 in the South Atlantic. Outpatient mortality ranged from $0.3 \%$ in the Pacific region to $0.1 \%$ in New England. The CCI for inpatient visits ranged from a low of 0.7 in the West South Central region to a high of 2.5 in the South Atlantic. Inpatient mortality ranged from $1.9 \%$ in the West South Central region to $4.8 \%$ in New England. Alcohol disorders, anxiety disorders, and depression were the most common comorbid conditions reported. The outpatient setting rates of hepatitis (acute and chronic) ranged from $0.4 \%$, West North Central, to 4.0\%, Mountain. Hepatitis (acute and chronic) was considerably more prevalent in the inpatient population and ranged from $4.0 \%$, West North Central, to a high of $21.3 \%$, New England.

The most common procedure across all regions performed for inpatient opioid-related visits was detoxification, whereas the most common procedure in the outpatient setting was injection of a therapeutic substance (ie, buprenorphine and naloxone). Inpatient opioid-related visits generally originated through the ED, and outpatient opioid-related visits were generally elective visits. Those opioid-related visits resulting in an admission had an average LOS of 4.4 days (range: $3.8-5.7$ ).

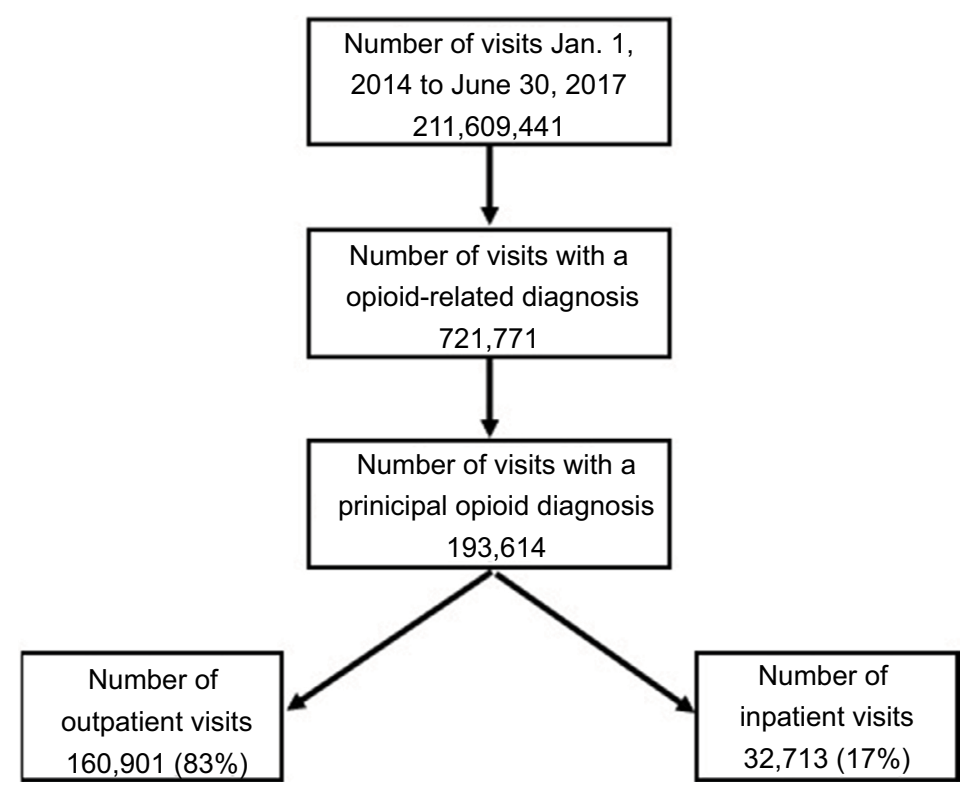

Figure I Attrition diagram

Note: ICD, ninth and tenth revision (ICD-9/I0), diagnosis codes: 304.0x, 304.7x, 305.5x, 965.0x, FII.x, and T40.0x to T40.3x were used to identify principal opioid diagnosis. 
Table I Patient characteristics

\begin{tabular}{|c|c|c|c|c|c|c|c|c|}
\hline & \multicolumn{2}{|c|}{$\begin{array}{l}\text { East North } \\
\text { Central }\end{array}$} & \multicolumn{2}{|c|}{$\begin{array}{l}\text { East South } \\
\text { Central }\end{array}$} & \multicolumn{2}{|c|}{ Mid-Atlantic } & \multicolumn{2}{|c|}{ Mountain } \\
\hline & OP & IP & OP & IP & OP & IP & OP & IP \\
\hline \multicolumn{9}{|l|}{ Total visits } \\
\hline Total & 22,069 & 3,673 & 10,438 & 2,866 & 22,191 & 3,708 & 4,292 & 613 \\
\hline \multicolumn{9}{|l|}{ Gender } \\
\hline Male & $52 \%$ & $57 \%$ & $40 \%$ & $47 \%$ & $52 \%$ & $60 \%$ & $47 \%$ & $48 \%$ \\
\hline Female & $48 \%$ & $43 \%$ & $60 \%$ & $53 \%$ & $48 \%$ & $40 \%$ & $53 \%$ & $52 \%$ \\
\hline \multicolumn{9}{|l|}{ Age } \\
\hline Age (years) - mean (SD) & $\begin{array}{l}36.49 \\
(12.5)\end{array}$ & $\begin{array}{l}42.6 \\
(15.5)\end{array}$ & $\begin{array}{l}36.47 \\
(12.4)\end{array}$ & $\begin{array}{l}40.5 \\
(14.7)\end{array}$ & \begin{tabular}{|l|}
35.05 \\
$(12.4)$
\end{tabular} & $\begin{array}{l}38.9 \\
(15.0)\end{array}$ & \begin{tabular}{|l|}
37.8 \\
$(14.6)$
\end{tabular} & \begin{tabular}{|l|}
46.5 \\
$(17.9)$
\end{tabular} \\
\hline \multicolumn{9}{|l|}{ Admission source } \\
\hline Elective & $51 \%$ & $38 \%$ & $65 \%$ & $4 \%$ & $45 \%$ & $17 \%$ & $37 \%$ & $7 \%$ \\
\hline Emergency & $40 \%$ & $55 \%$ & $28 \%$ & $64 \%$ & $38 \%$ & $71 \%$ & $61 \%$ & $83 \%$ \\
\hline Urgent & $0 \%$ & $5 \%$ & $1 \%$ & $8 \%$ & $1 \%$ & $5 \%$ & $1 \%$ & $10 \%$ \\
\hline Missing/unknown & $9 \%$ & $1 \%$ & $6 \%$ & $25 \%$ & $15 \%$ & $7 \%$ & $0 \%$ & $1 \%$ \\
\hline \multicolumn{9}{|l|}{ Discharge destination } \\
\hline Home & $59 \%$ & $65 \%$ & $41 \%$ & $72 \%$ & $95 \%$ & $58 \%$ & $85 \%$ & $62 \%$ \\
\hline Post-acute care & $0 \%$ & $6 \%$ & $0 \%$ & $5 \%$ & $0 \%$ & $16 \%$ & $1 \%$ & $13 \%$ \\
\hline Transfer & $2 \%$ & $6 \%$ & $3 \%$ & $6 \%$ & $2 \%$ & $8 \%$ & $4 \%$ & $11 \%$ \\
\hline Left AMA & $2 \%$ & $11 \%$ & $3 \%$ & $14 \%$ & $3 \%$ & $15 \%$ & $3 \%$ & $8 \%$ \\
\hline Others & $7 \%$ & $1 \%$ & $1 \%$ & $0 \%$ & $0 \%$ & $0 \%$ & $3 \%$ & $1 \%$ \\
\hline Missing/unknown & $30 \%$ & $9 \%$ & $53 \%$ & $1 \%$ & $1 \%$ & $0 \%$ & $3 \%$ & $1 \%$ \\
\hline \multicolumn{9}{|l|}{ Payer } \\
\hline Commercial & $27 \%$ & $18 \%$ & $20 \%$ & $17 \%$ & $25 \%$ & $25 \%$ & $5 \%$ & $7 \%$ \\
\hline Medicaid & $32 \%$ & $21 \%$ & $11 \%$ & $20 \%$ & $49 \%$ & $34 \%$ & $14 \%$ & $14 \%$ \\
\hline Medicare & $10 \%$ & $18 \%$ & $12 \%$ & $23 \%$ & $7 \%$ & $15 \%$ & $5 \%$ & $13 \%$ \\
\hline Others & $4 \%$ & $3 \%$ & $10 \%$ & $10 \%$ & $8 \%$ & $5 \%$ & $4 \%$ & $3 \%$ \\
\hline Unknown & $27 \%$ & $41 \%$ & $47 \%$ & $30 \%$ & $11 \%$ & $21 \%$ & $71 \%$ & $64 \%$ \\
\hline \multicolumn{9}{|l|}{ Charlson comorbidities } \\
\hline $\mathrm{CCl}$ - mean (SD) & $\begin{array}{l}0.44 \\
(1.2)\end{array}$ & $\begin{array}{l}.14 \\
(2.1)\end{array}$ & $\begin{array}{l}0.53 \\
(1.5)\end{array}$ & $\begin{array}{l}0.95 \\
(1.9)\end{array}$ & $\begin{array}{l}0.45 \\
(1.4)\end{array}$ & $\begin{array}{l}0.96 \\
(2.1)\end{array}$ & \begin{tabular}{|l|}
0.69 \\
$(1.8)$ \\
\end{tabular} & $\begin{array}{l}1.70 \\
(2.5) \\
\end{array}$ \\
\hline \multicolumn{9}{|l|}{ Other comorbidities } \\
\hline Alcohol disorders & $5 \%$ & $12 \%$ & $2 \%$ & $13 \%$ & $15 \%$ & $18 \%$ & $6 \%$ & $17 \%$ \\
\hline Anxiety disorders & $7 \%$ & $22 \%$ & $3 \%$ & $26 \%$ & $7 \%$ & $24 \%$ & $10 \%$ & $19 \%$ \\
\hline Bipolar disorder & $2 \%$ & $6 \%$ & $2 \%$ & $12 \%$ & $4 \%$ & $12 \%$ & $2 \%$ & $7 \%$ \\
\hline Depression & $6 \%$ & $25 \%$ & $3 \%$ & $23 \%$ & $4 \%$ & $23 \%$ & $8 \%$ & $20 \%$ \\
\hline Hepatitis (acute and chronic) & $3 \%$ & $14 \%$ & $1 \%$ & $17 \%$ & $2 \%$ & $12 \%$ & $4 \%$ & $16 \%$ \\
\hline History of substance abuse & $2 \%$ & $5 \%$ & $2 \%$ & $8 \%$ & $2 \%$ & $7 \%$ & $1 \%$ & $8 \%$ \\
\hline \multicolumn{9}{|l|}{ Mortality } \\
\hline Mortality & $0.1 \%$ & $2.3 \%$ & $0.1 \%$ & $1.2 \%$ & $0.1 \%$ & $2.2 \%$ & $0.1 \%$ & $3.3 \%$ \\
\hline
\end{tabular}

Note: Only comorbid conditions occurring in at least $5 \%$ of visits in one or more regions are given.

Abbreviations: AMA, against medical advice; $\mathrm{CCl}$, Charlson Comorbidity Index; IP, inpatient; OP, outpatient.

The characteristics of the hospitals by region and care setting are summarized in Table 2. Generally, the hospitals were nonprofit, located in urban areas, and had both inpatient and outpatient opioid-related visits. Most hospitals treating opioid-related visits in the study population were nonteaching hospitals. The exception was in the East South Central region, where teaching hospitals composed $58.0 \%$ and $60.0 \%$ of hospitals treating outpatient and inpatient opioid-related visits, respectively.

The overall unadjusted average cost of an opioid-related visit was $\$ 532$ and $\$ 6,853$ for outpatient and inpatient vis- its, respectively (Table S1). Correspondingly, the overall unadjusted payment was $\$ 585$ for outpatient and $\$ 8,731$ for inpatient visits. The East South Central region had the lowest outpatient and inpatient costs ( $\$ 341$ and $\$ 4,314$ ). The highest payment was in the West South Central (\$746) and Pacific $(\$ 9,873)$ regions for outpatient and inpatient visits, respectively. The overall average LOS was 5.5 days with a range of 4.3 (East North Central region) to 7.1 (Mid-Atlantic region).

The adjusted estimates for outpatient and inpatient opioid visits by the nine regions are reported in Table 3. The models included patient and hospital characteristics and are summa- 


\begin{tabular}{|c|c|c|c|c|c|c|c|c|c|}
\hline \multicolumn{2}{|c|}{ New England } & \multicolumn{2}{|l|}{ Pacific } & \multicolumn{2}{|c|}{ South Atlantic } & \multicolumn{2}{|c|}{$\begin{array}{l}\text { West North } \\
\text { Central }\end{array}$} & \multicolumn{2}{|c|}{$\begin{array}{l}\text { West South } \\
\text { Central }\end{array}$} \\
\hline OP & IP & OP & IP & OP & IP & OP & IP & OP & IP \\
\hline 18,407 & 933 & 25,426 & 5,146 & 38,253 & 9,030 & 2,464 & 528 & $|7,35|$ & 5,916 \\
\hline $\begin{array}{l}58 \% \\
42 \% \\
\end{array}$ & $\begin{array}{l}62 \% \\
38 \%\end{array}$ & \begin{tabular}{|l|}
$57 \%$ \\
$43 \%$ \\
\end{tabular} & $\begin{array}{l}58 \% \\
42 \% \\
\end{array}$ & $\begin{array}{l}54 \% \\
46 \% \\
\end{array}$ & $\begin{array}{l}51 \% \\
49 \% \\
\end{array}$ & \begin{tabular}{|l|}
$40 \%$ \\
$60 \%$ \\
\end{tabular} & $\begin{array}{l}42 \% \\
58 \% \\
\end{array}$ & \begin{tabular}{|l|}
$54 \%$ \\
$46 \%$ \\
\end{tabular} & $\begin{array}{l}51 \% \\
49 \% \\
\end{array}$ \\
\hline $\begin{array}{l}36.63 \\
(12.4) \\
\end{array}$ & $\begin{array}{l}43.8 \\
(16.7)\end{array}$ & $\begin{array}{l}37.65 \\
(14.2) \\
\end{array}$ & $\begin{array}{l}43.4 \\
(17.9) \\
\end{array}$ & $\begin{array}{l}38.77 \\
(15.2) \\
\end{array}$ & $\begin{array}{l}44.7 \\
(17.0) \\
\end{array}$ & \begin{tabular}{|l|}
37.77 \\
$(12.7)$ \\
\end{tabular} & $\begin{array}{l}48.6 \\
(17.5) \\
\end{array}$ & $\begin{array}{l}40.23 \\
(15.7) \\
\end{array}$ & $\begin{array}{l}43.8 \\
(17.4) \\
\end{array}$ \\
\hline $\begin{array}{l}59 \% \\
35 \% \\
1 \% \\
5 \% \\
\end{array}$ & $\begin{array}{l}3 \% \\
83 \% \\
9 \% \\
5 \% \\
\end{array}$ & \begin{tabular}{|l|}
$27 \%$ \\
$43 \%$ \\
$2 \%$ \\
$28 \%$ \\
\end{tabular} & $\begin{array}{l}11 \% \\
59 \% \\
18 \% \\
12 \% \\
\end{array}$ & $\begin{array}{l}35 \% \\
53 \% \\
3 \% \\
9 \% \\
\end{array}$ & $\begin{array}{l}5 \% \\
70 \% \\
14 \% \\
11 \% \\
\end{array}$ & \begin{tabular}{|l|}
$63 \%$ \\
$26 \%$ \\
$9 \%$ \\
$2 \%$ \\
\end{tabular} & $\begin{array}{l}2 \% \\
51 \% \\
41 \% \\
6 \% \\
\end{array}$ & \begin{tabular}{|l|}
$33 \%$ \\
$52 \%$ \\
$2 \%$ \\
$13 \%$ \\
\end{tabular} & $\begin{array}{l}24 \% \\
55 \% \\
16 \% \\
5 \% \\
\end{array}$ \\
\hline $\begin{array}{l}67 \% \\
0 \% \\
2 \% \\
3 \% \\
0 \% \\
28 \% \\
\end{array}$ & $\begin{array}{l}51 \% \\
14 \% \\
11 \% \\
9 \% \\
1 \% \\
9 \% \\
\end{array}$ & $\begin{array}{l}93 \% \\
0 \% \\
2 \% \\
2 \% \\
1 \% \\
1 \% \\
\end{array}$ & $\begin{array}{l}62 \% \\
15 \% \\
8 \% \\
12 \% \\
1 \% \\
1 \% \\
\end{array}$ & $\begin{array}{l}83 \% \\
1 \% \\
5 \% \\
4 \% \\
1 \% \\
6 \% \\
\end{array}$ & $\begin{array}{l}67 \% \\
12 \% \\
9 \% \\
6 \% \\
1 \% \\
2 \% \\
\end{array}$ & \begin{tabular}{|l|}
$91 \%$ \\
$1 \%$ \\
$3 \%$ \\
$2 \%$ \\
$1 \%$ \\
$2 \%$ \\
\end{tabular} & $\begin{array}{l}59 \% \\
15 \% \\
14 \% \\
3 \% \\
0 \% \\
5 \% \\
\end{array}$ & $\begin{array}{l}71 \% \\
1 \% \\
6 \% \\
3 \% \\
3 \% \\
15 \% \\
\end{array}$ & $\begin{array}{l}66 \% \\
12 \% \\
8 \% \\
7 \% \\
0 \% \\
3 \% \\
\end{array}$ \\
\hline $\begin{array}{l}24 \% \\
23 \% \\
16 \% \\
1 \% \\
36 \% \\
\end{array}$ & $\begin{array}{l}26 \% \\
21 \% \\
29 \% \\
1 \% \\
23 \% \\
\end{array}$ & $\begin{array}{l}26 \% \\
32 \% \\
12 \% \\
2 \% \\
28 \% \\
\end{array}$ & $\begin{array}{l}46 \% \\
17 \% \\
24 \% \\
3 \% \\
10 \% \\
\end{array}$ & $\begin{array}{l}24 \% \\
15 \% \\
14 \% \\
15 \% \\
32 \% \\
\end{array}$ & $\begin{array}{l}22 \% \\
17 \% \\
24 \% \\
12 \% \\
24 \% \\
\end{array}$ & \begin{tabular}{|l|}
$19 \%$ \\
$19 \%$ \\
$20 \%$ \\
$4 \%$ \\
$38 \%$ \\
\end{tabular} & $\begin{array}{l}22 \% \\
11 \% \\
35 \% \\
2 \% \\
30 \% \\
\end{array}$ & $\begin{array}{l}28 \% \\
19 \% \\
18 \% \\
10 \% \\
24 \% \\
\end{array}$ & $\begin{array}{l}24 \% \\
15 \% \\
25 \% \\
9 \% \\
26 \% \\
\end{array}$ \\
\hline $\begin{array}{l}0.67 \\
(1.6) \\
\end{array}$ & $\begin{array}{l}I .5 I \\
(2.5) \\
\end{array}$ & $\begin{array}{l}0.54 \\
(1.5) \\
\end{array}$ & $\begin{array}{l}2.2 \\
(1.5) \\
\end{array}$ & $\begin{array}{l}0.76 \\
(1.8) \\
\end{array}$ & $\begin{array}{l}2.52 \\
(1.7) \\
\end{array}$ & \begin{tabular}{|l|}
0.52 \\
$(1.2)$ \\
\end{tabular} & $\begin{array}{l}1.72 \\
(2.6) \\
\end{array}$ & $\begin{array}{l}0.73 \\
(1.8) \\
\end{array}$ & \begin{tabular}{|l|}
0.73 \\
$(2.4)$ \\
\end{tabular} \\
\hline $\begin{array}{l}5 \% \\
4 \% \\
1 \% \\
4 \% \\
3 \% \\
1 \% \\
\end{array}$ & $\begin{array}{l}17 \% \\
19 \% \\
6 \% \\
23 \% \\
21 \% \\
8 \% \\
\end{array}$ & $\begin{array}{l}4 \% \\
7 \% \\
2 \% \\
6 \% \\
3 \% \\
1 \% \\
\end{array}$ & $\begin{array}{l}22 \% \\
34 \% \\
9 \% \\
31 \% \\
13 \% \\
8 \% \\
\end{array}$ & $\begin{array}{l}5 \% \\
8 \% \\
2 \% \\
7 \% \\
3 \% \\
2 \% \\
\end{array}$ & $\begin{array}{l}15 \% \\
21 \% \\
9 \% \\
25 \% \\
10 \% \\
6 \% \\
\end{array}$ & \begin{tabular}{|l|}
$1 \%$ \\
$2 \%$ \\
$1 \%$ \\
$2 \%$ \\
$0 \%$ \\
$1 \%$ \\
\end{tabular} & $\begin{array}{l}7 \% \\
15 \% \\
3 \% \\
19 \% \\
4 \% \\
5 \% \\
\end{array}$ & $\begin{array}{l}4 \% \\
6 \% \\
2 \% \\
6 \% \\
3 \% \\
2 \% \\
\end{array}$ & $\begin{array}{l}12 \% \\
19 \% \\
7 \% \\
21 \% \\
14 \% \\
7 \% \\
\end{array}$ \\
\hline $0.1 \%$ & $4.8 \%$ & $0.0 \%$ & $2.0 \%$ & $0.1 \%$ & $2.6 \%$ & $0.1 \%$ & $2.7 \%$ & $0.1 \%$ & $1.9 \%$ \\
\hline
\end{tabular}

rized in Tables 1 and 2 as these covariates were found to be significant predictors of the outcome variables. The overall outpatient adjusted estimates were $\$ 533$ and $\$ 374$ for cost and payment, respectively. The Mid-Atlantic region had the lowest outpatient cost (\$395), and the Mid-Atlantic region had the lowest outpatient payment (\$187). The highest cost and payment regions for outpatient visits were West South Central (\$802) and Pacific (\$574). In the inpatient setting, the overall adjusted cost, payment, and LOS were $\$ 4,383, \$ 6,689$, and 4.4 days, respectively. The region with the lowest estimated cost and payment was East South Central at $\$ 2,894$ and $\$ 4,038$, respectively. The lowest LOS was found in East North Central and Mountain regions at an average of 3.8 days. The regions with the highest cost, payment, and LOS were Pacific $(\$ 6,671)$, Mountain, (\$9,001), and Mid-Atlantic (5.7 days), respectively.

Hospital benefit or loss, the difference between adjusted mean payment and cost, varied considerably across the regions (Figure 2). In the outpatient setting, hospitals were predicted to lose $\$ 159$ per opioid-related visit, although there was nearly a fourfold difference between the regions with the highest profit margin (East South Central, \$119) and the lowest (West South Central, \$326). In the inpatient setting, the typical hospital was 


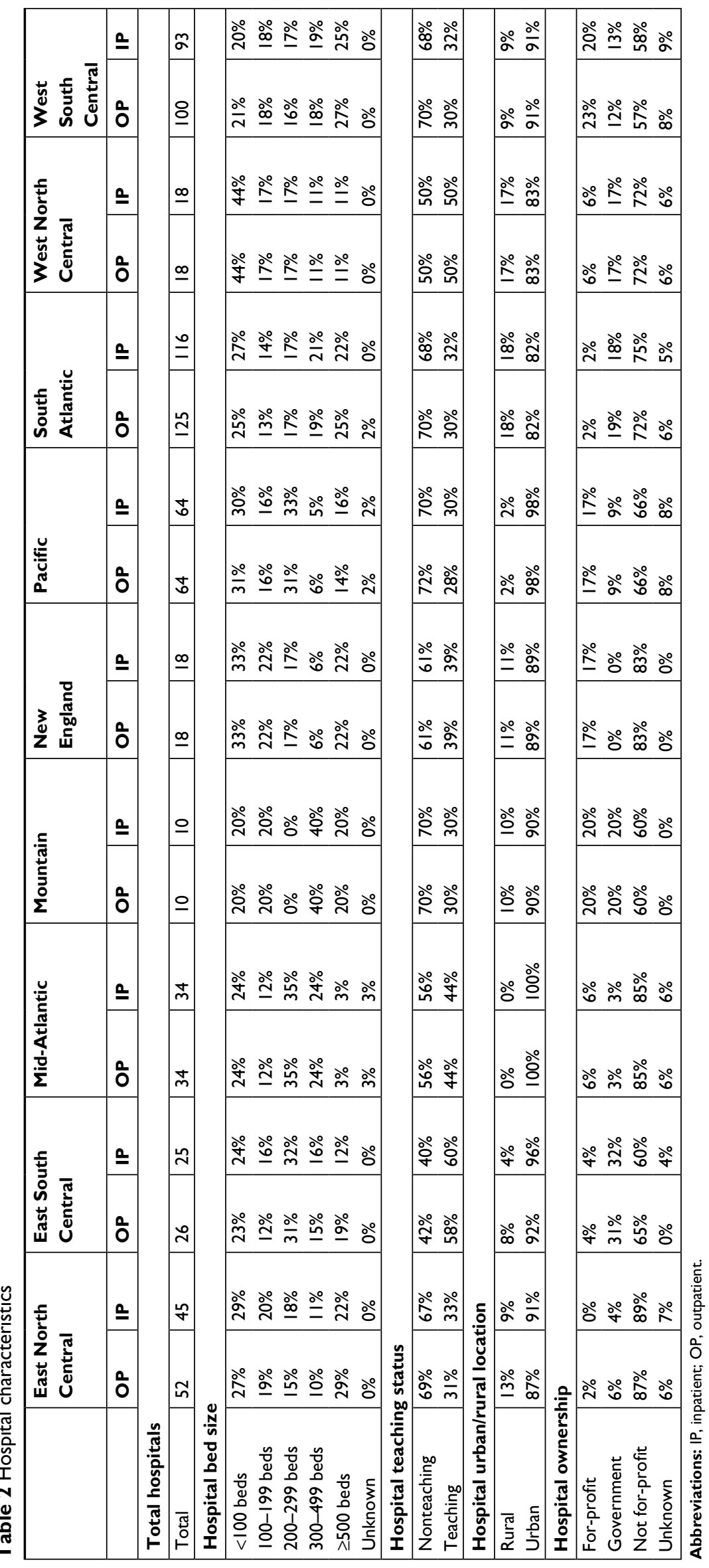


Table 3 Adjusted cost, payment, and LOS

\begin{tabular}{|c|c|c|c|c|c|c|}
\hline & \multicolumn{3}{|c|}{ Outpatient } & \multicolumn{3}{|c|}{ Inpatient } \\
\hline & Mean & \multicolumn{2}{|c|}{$95 \% \mathrm{Cl}$} & Mean & \multicolumn{2}{|c|}{$95 \% \mathrm{Cl}$} \\
\hline \multicolumn{7}{|l|}{ Costs } \\
\hline East North Central & $\$ 488$ & $\$ 387$ & $\$ 616$ & $\$ 3,336$ & $\$ 2,705$ & $\$ 4,115$ \\
\hline East South Central & $\$ 408$ & $\$ 323$ & $\$ 515$ & $\$ 2,894$ & $\$ 2,347$ & $\$ 3,569$ \\
\hline Mid-Atlantic & $\$ 395$ & $\$ 313$ & $\$ 499$ & $\$ 5,835$ & $\$ 4,733$ & $\$ 7,195$ \\
\hline Mountain & $\$ 569$ & $\$ 450$ & $\$ 720$ & $\$ 4,472$ & $\$ 3,596$ & $\$ 5,562$ \\
\hline New England & $\$ 429$ & $\$ 340$ & $\$ 541$ & $\$ 4,885$ & $\$ 3,953$ & $\$ 6,035$ \\
\hline Pacific & $\$ 610$ & $\$ 483$ & $\$ 769$ & $\$ 6,671$ & $\$ 5,412$ & $\$ 8,224$ \\
\hline South Atlantic & $\$ 698$ & $\$ 553$ & $\$ 881$ & $\$ 3,979$ & $\$ 3,231$ & $\$ 4,900$ \\
\hline West North Central & $\$ 530$ & $\$ 419$ & $\$ 672$ & $\$ 5,192$ & $\$ 4,169$ & $\$ 6,467$ \\
\hline West South Central & $\$ 802$ & $\$ 635$ & $\$ 1,012$ & $\$ 3,520$ & $\$ 2,857$ & $\$ 4,337$ \\
\hline Overall & $\$ 533$ & $\$ 422$ & $\$ 673$ & $\$ 4,383$ & $\$ 3,561$ & $\$ 5,394$ \\
\hline \multicolumn{7}{|l|}{ Payment } \\
\hline East North Central & $\$ 281$ & $\$ 157$ & $\$ 502$ & $\$ 7,984$ & $\$ 6,111$ & $\$|0,43|$ \\
\hline East South Central & $\$ 527$ & $\$ 293$ & $\$ 949$ & $\$ 4,038$ & $\$ 3,090$ & $\$ 5,278$ \\
\hline Mid-Atlantic & $\$ 187$ & $\$ 104$ & $\$ 334$ & $\$ 7,070$ & $\$ 5,428$ & $\$ 9,209$ \\
\hline Mountain & $\$ 319$ & $\$ 175$ & $\$ 580$ & $\$ 9,001$ & $\$ 6,406$ & $\$ 12,647$ \\
\hline New England & $\$ 245$ & $\$ 137$ & $\$ 438$ & $\$ 7,897$ & $\$ 6,051$ & $\$ 10,305$ \\
\hline Pacific & $\$ 574$ & $\$ 321$ & $\$ 1,028$ & $\$ 8,183$ & $\$ 6,291$ & $\$ 10,644$ \\
\hline South Atlantic & $\$ 434$ & $\$ 242$ & $\$ 776$ & $\$ 5,55 \mathrm{I}$ & $\$ 4,271$ & $\$ 7,216$ \\
\hline West North Central & $\$ 567$ & $\$ 311$ & $\$ 1,034$ & $\$ 6,490$ & $\$ 4,760$ & $\$ 8,850$ \\
\hline West South Central & $\$ 476$ & $\$ 266$ & $\$ 852$ & $\$ 5,617$ & $\$ 4,319$ & $\$ 7,305$ \\
\hline Overall & $\$ 374$ & $\$ 209$ & $\$ 670$ & $\$ 6,689$ & $\$ 5,146$ & $\$ 8,696$ \\
\hline \multicolumn{7}{|l|}{ LOS, days } \\
\hline East North Central & & & & 3.8 & 3.2 & 4.4 \\
\hline East South Central & & & & 4.4 & 3.8 & 5.2 \\
\hline Mid-Atlantic & & & & 5.7 & 4.9 & 6.7 \\
\hline Mountain & & & & 3.8 & 3.3 & 4.5 \\
\hline New England & & & & 4.4 & 3.8 & 5.2 \\
\hline Pacific & & & & 5.0 & 4.2 & 5.8 \\
\hline South Atlantic & & & & 4.2 & 3.6 & 5.0 \\
\hline West North Central & & & & 4.0 & 3.4 & 4.7 \\
\hline West South Central & & & & 4.1 & 3.5 & 4.9 \\
\hline Overall & & & & 4.4 & 3.7 & 5.1 \\
\hline
\end{tabular}

Abbreviation: LOS, length of stay.

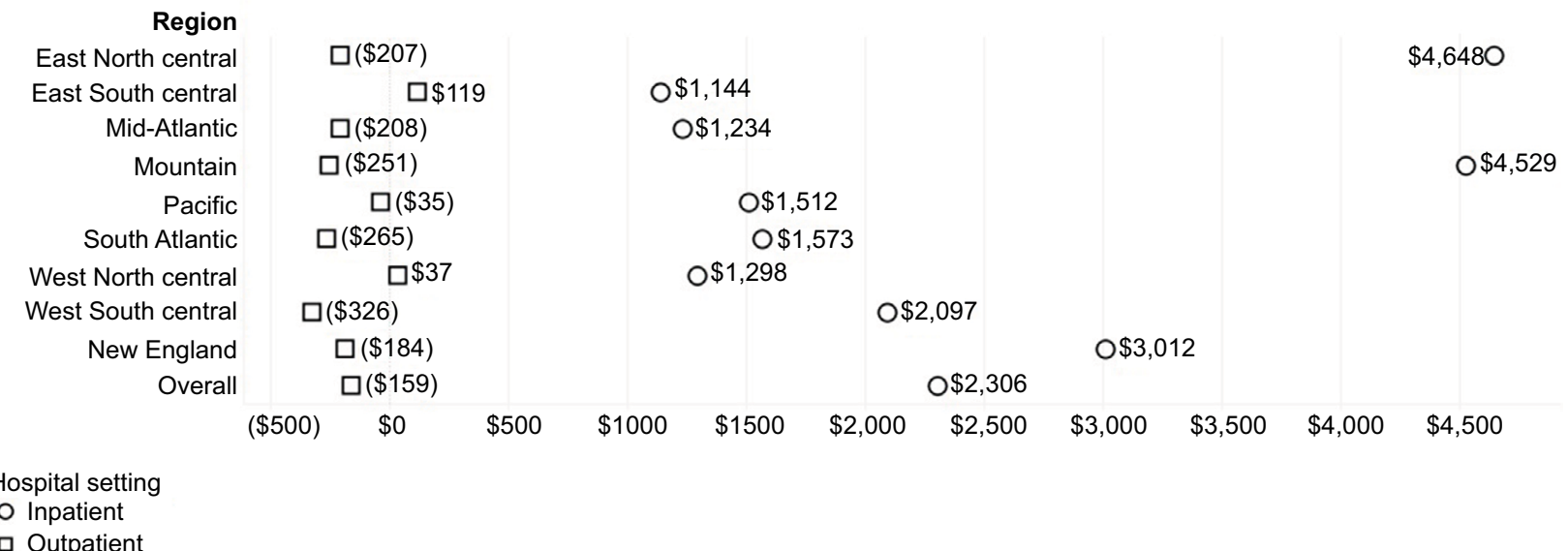

Figure 2 Hospital net benefit/loss based on adjusted mean results. 
expected to profit $\$ 2,306$ per visit. The variation across regions was similar to the outpatient setting with a fourfold difference between the regions with the highest profit margin (East North Central, \$4,648) and the lowest (East South Central, \$1,144).

\section{Discussion}

Not surprisingly, this study found a wide geographic variation in costs, payments, and LOS for opioid-related hospital visits even after adjusting for patient demographics and hospital characteristics. These findings provide insight into the opioid crisis in the hospital setting due to the recentness of the data and the provision of regional adjusted estimates. The requirement of an opioid-related principal diagnosis code provided a reliable depiction of the opioid crisis from the hospital perspective. ${ }^{21-24}$ Hospitals might use this information to benchmark their own opioid-related visits with hospitals in their region to understand the burden of the opioid epidemic.

Hospitals overall were expected to have a net loss of \$159 per outpatient opioid-related visit. In five of the nine regions, the hospital outpatient department had a net loss of more than $\$ 200$ per opioid visit. The high propensity of elective outpatient hospital visits combined with procedures for injecting therapeutic substances suggests that patients are receiving addiction-related treatment and the hospital received less than the amount necessary to cover their services. The data used for this analysis cannot confirm this hypothesis, but if it were true, it suggests a potent disincentive for a hospital to provide services for patients seeking treatment for opioid abuse and misuse. Further, this finding complements studies that have found significant variation in addiction-related treatment capacity. ${ }^{26-28}$ The hospital outpatient department may be the setting of last resort for those unable to access treatment elsewhere.

Inpatient opioid-related visits provided on average a net benefit of $\$ 2,306$ per visit. The substantial net benefit appears to provide an incentive to the hospital to initiate a treatment program. Although there was a wide variation in the magnitude of the net benefit, hospitals in all nine regions received a higher payment for an opioid-related inpatient visit compared to the cost with a minimum of $\$ 1,100$ after costs across all regions. The East North Central region had the highest net benefit of $\$ 4,648$, closely followed by the Mountain region.

Although most patients treated in the hospital inpatient setting were discharged to home, approximately one in 10 patients, regardless of region, was likely to leave against medical advice, suggesting that he/she did not complete the detoxification treatment or his/her pain was undertreated. Further, less than $12 \%$ of inpatient opioid-related visits were discharged to a post-acute care facility to continue their treatment.
This is the first study to examine the health care utilization (cost, payment, and LOS) of opioid-related visits from the hospital perspective. This particular population is a vulnerable population with higher (ED) utilization, hospitalizations, and increased healthcare utilization compared to patients with no opioids in their system. ${ }^{22,26,27}$ Consistent with the published research on geographic variation in healthcare utilization and spending, the findings of this study indicate a wide geographic variation in hospital-provided health care utilization for opioid-related visits. ${ }^{29}$ Further, this study found that outpatient opioid-related visits may not be financially viable for the hospital. Changes in payment structure or perhaps greater availability and accessibility to less intensive sites of care for treatments related to opioid abuse may be necessary to effectively manage this population.

\section{Limitations}

The use of hospital administrative claims data incurs several noteworthy limitations. First, the data used in the analysis included 451 hospitals across the US. The hospitals are not nationally representative, although the large number of visits and hospitals in each US region compare favorably to the distribution of hospitals in the American Hospital Association Survey. ${ }^{29}$ Second, the use of claims data may underreport the occurrence of opioid-related visits due to the stigma associated with drug use. ${ }^{30}$ Furthermore, the primary purpose of hospital claims data is to support the financial accounting of the hospital rather than capture complete clinical data. Thus, it is possible that relevant clinical information on the severity of the visit was missing. However, we have no reason to suspect that this possible bias either overestimates or underestimates our results. ${ }^{31,32}$ It is also important to note that data used in this analysis did not allow examination of visits at smaller geographic levels, repeat visits, and secondary diagnoses indicating the presence of opioids or to follow the patient across the continuum of care postdischarge. Despite these limitations, hospital claims data remain an important source of health data, especially when investigating health care utilization. ${ }^{33}$

\section{Conclusion}

This study demonstrated that there is significant geographic variation in the mean hospital cost, payment, and LOS for an opioid-related visit across the nine US regions after accounting for differences in patient and hospital characteristics. The estimates of cost, payment, and LOS will enable healthcare providers and policy makers to better estimate the impact of the opioid epidemic for their specific geographic region by care setting. As hospitals take a more active role in the 
opioid epidemic, having regional data on costs, payments, and LOS in addition to national data will allow for more effective benchmarking. Future research should examine the role of price and intensity of services to ascertain the practices, which may alleviate this significant burden on hospitals and payers.

\section{Acknowledgments}

The authors would like to thank Vizient Inc. for providing the data used in this study and Mrs Kristin Dale for her thoughtful comments to an earlier draft of this study.

\section{Disclosure}

The authors report no conflicts of interest in this work.

\section{References}

1. The Underestimated Cost of the Opioid Crisis. White House Council of Economic Advisers (CEA); 2017. Available at: https://www.whitehouse. gov/sites/whitehouse.gov/files/images/The $\% 20$ Underestimated $\% 20$ Cost $\% 20$ of $\% 20$ the $\% 20$ Opioid $\% 20$ Crisis.pdf. Accessed November 25 , 2017.

2. Rhyan CN. The Potential Societal Benefit of Eliminating Opioid Overdoses, Deaths, and Substance Abuse Disorders Exceeds \$95 Billion Per Year. Ann Arbor: Altarum, Inc.; 2017.

3. Florence CS, Zhou C, Luo F, Xu L. The economic burden of prescription opioid overdose, abuse, and dependence in the United States, 2013. Med Care. 2016;54(10):901-906.

4. Drug Poisoning Mortality in the United States, 1999-2015 [Homepage on the Internet]. National Center for Health Statistics (NCHS): Centers for Disease Control and Prevention. Available from: https://www. cdc.gov/nchs/data-visualization/drug-poisoning-mortality/. Accessed November 29, 2017.

5. Managing Population Health. The Role of the Hospital. Health Research \& Educational Trust. Chicago: Managing Population Health; 2012.

6. Stevens JP, Wall MJ, Novack L, Marshall J, Hsu DJ, Howell MD. The critical care crisis of opioid overdoses in the United States. Ann Am Thorac Soc. 2017;14(12):1803-1809.

7. Hsu DJ, Mccarthy EP, Stevens JP, Mukamal KJ. Hospitalizations, costs and outcomes associated with heroin and prescription opioid overdoses in the United States 2001-12. Addiction. 2017;112(9):1558-1564.

8. HCUP Fast Stats [homepage on the Internet]. Healthcare Cost and Utilization Project (HCUP). Rockville, MD, USA: Agency for Healthcare Research and Quality; 2017. Available from: www. hcup-us.ahrq.gov/faststats/opioid/opioiduse.jsp?location1=US\&char acteristic $1=01 \&$ setting $1=$ IP \&location $2=U S \&$ characteristic $2=01 \&$ se tting $2=E D \&$ expansionInfoState $=$ hide $\&$ dataTablesState $=$ hide $\&$ defin itionsState=hide\&exportState=hide. Accessed October 30, 2018.

9. Weiss AJ, Bailey MK, O'Malley L. Patient Characteristics of OpioidRelated Inpatient Stays and Emergency Department Visits Nationally and by State, 2014. Rockville: Agency for Healthcare Research and Quality; 2017.

10. Krueger AB. Where Have All the Workers Gone? An Inquiry into the Decline of the U.S. Labor Force Participation Rate. Brookings Papers on Economic Activity (BPEA); 2017:1-87.

11. Topmiller M, Vissman A, Carrozza M, et al. Determining MedicationAssisted Treatment (MAT) Capacity in High Need Areas. Poster presented at the: North American Primary Care Research Group (NAPCRG) 45th Annual Meeting; November 2017; Montreal, Quebec.

12. Weiss AJ, Elixhauser A, Barrett ML. Opioid-Related Inpatient Stays and Emergency Department Visits by State, 2009-2014. Rockville, MD, USA: Agency for Healthcare Research and Quality; 2016.
13. Cubanski J, Neuman $\mathrm{T}$ [homepage on the Internet]. The Latest on Geographic Variation in Medicare Spending: A Demographic Divide Persists but Variation Has Narrowed. Washington, DC: Kaiser Family Foundation; 2015. Available from: https://www.kff.org/medicare/ report/the-latest-on-geographic-variation-in-medicare-spending-ademographic-divide-persists-but-variation-has-narrowed/. Accessed October 30, 2018.

14. Newhouse JP, Garber AM. Geographic variation in health care spending in the United States: insights from an institute of medicine report. JAMA. 2013;310(12):1227-1228.

15. Baicker K, Amitabh C, Skinner JS. Who you are and where you live: how race and geography affect the treatment of medicare beneficiaries. Health Aff (Millwood). 2004:33-44.

16. Skinner J, Fisher E. Regional disparities in Medicare expenditures: an opportunity for reform. Natl Tax J. 1997;50(3):413-425.

17. Bai G, Anderson GF. A more detailed understanding of factors associated with hospital profitability. Health Aff. 2016;35(5): 889-897.

18. Clarke JL, Skoufalos A, Scranton R. The American opioid epidemic: population health implications and potential solutions. report from the national stakeholder panel. Population Health Management. 2016;19:S1-S10

19. Horwitz JR. Making profits and providing care: comparing nonprofit, for-profit, and government hospitals. Health Aff. 2005;24(3):790-801.

20. IncVizient. New Hanover Regional Medical Center; 2017. Available from: www.vizientinc.com. Accessed January 23, 2018.

21. Chandwani HS, Strassels SA, Rascati KL, Lawson KA, Wilson JP. Estimates of charges associated with emergency department and hospital inpatient care for opioid abuse-related events. J Pain Palliat Care Pharmacother. 2013;27(3):206-213.

22. White AG, Birnbaum HG, Mareva MN, et al. Direct costs of opioid abuse in an insured population in the United States. $J$ Manag Care Pharm. 2005;11(6):469-479.

23. Heslin KC, Owens PL, Karaca Z, Barrett ML, Moore BJ, Elixhauser A. Trends in opioid-related inpatient stays shifted after the US Transitioned to ICD-10-CM Diagnosis Coding in 2015. Med Care. 2017;55(11):918-923.

24. American Psychiatric Association (APA). Diagnostic and Statistical Manual of Mental Disorders. 5th ed. Washington, DC: American Psychiatric Association; 2013.

25. Charlson M, Szatrowski TP, Peterson J, Gold J. Validation of a combined comorbidity index. J Clin Epidemiol. 1994;47(11):1245-1251.

26. Noska A, Mohan A, Wakeman S, Rich J, Boutwell A. Managing opioid use disorder during and after acute hospitalization: a case-based review clarifying Methadone regulation for acute care settings. JAddict Behav Ther Rehabil. 2015;4(2):1-12.

27. Shanahan CW, Beers D, Alford DP, Brigandi E, Samet JH. A transitional opioid program to engage hospitalized drug users. J Gen Intern Med. 2010;25(8):803-808.

28. Jones CM, Campopiano M, Baldwin G, Mccance-Katz E. National and state treatment need and capacity for opioid agonist medication-assisted treatment. Am J Public Health. 2015;105(8):e55-e63.

29. American Hospital Association [homepage on the Internet]. AHA Hospital Statistics 2018 Edition; 26 June 2018. Available from: https:// www.aha.org/statistics/2016-12-27-aha-hospital-statistics-2018-edition. Accessed October 30, 2018.

30. Ruetsch C. Empirical view of opioid dependence. J Manag Care Pharm. 2010;16(1 Suppl B):9-13.

31. Fisher ES, Whaley FS, Krushat WM, et al. The accuracy of Medicare's hospital claims data: progress has been made, but problems remain. Am J Public Health. 1992;82(2):243-248.

32. O'Malley KJ, Cook KF, Price MD, et al. Measuring diagnoses: ICD code accuracy. Health Serv Res. 2005;40(5 Pt 2):1620-1639.

33. Tessier-Sherman B, Galusha D, Taiwo OA, et al. Further validation that claims data are a useful tool for epidemiologic research on hypertension. BMC Public Health. 2013;13(1):33. 


\section{Supplementary material}

Table SI Unadjusted cost, payment, and LOS

\begin{tabular}{|c|c|c|c|c|c|c|c|c|}
\hline & \multicolumn{4}{|c|}{ Outpatient } & \multicolumn{4}{|c|}{ Inpatient } \\
\hline & Visits & Median & Mean & SD & Visits & Median & Mean & SD \\
\hline \multicolumn{9}{|l|}{ Costs } \\
\hline East North Central & 22,069 & $\$ 229$ & $\$ 463$ & $\$ 739$ & 3,673 & $\$ 2,686$ & $\$ 5,068$ & $\$ 8,409$ \\
\hline East South Central & 10,438 & $\$ 138$ & $\$ 341$ & $\$ 548$ & 2,866 & $\$ 2,868$ & $\$ 4,3 \mid 4$ & $\$ 6,882$ \\
\hline Mid-Atlantic & 22,191 & $\$ 172$ & $\$ 364$ & $\$ 557$ & 3,708 & $\$ 4,966$ & $\$ 8,445$ & $\$ 12,10 \mid$ \\
\hline Mountain & 4,292 & $\$ 195$ & $\$ 480$ & $\$ 764$ & 613 & $\$ 4,972$ & $\$ 7,710$ & $\$ 8,757$ \\
\hline New England & 18,407 & $\$ 195$ & $\$ 402$ & $\$ 590$ & 933 & $\$ 4,990$ & $\$ 7,827$ & $\$ 9,905$ \\
\hline Pacific & 25,426 & $\$ 260$ & $\$ 596$ & $\$ 944$ & 5,146 & $\$ 6,592$ & $\$ 9,873$ & $\$ 12,783$ \\
\hline South Atlantic & 38,253 & $\$ 418$ & $\$ 650$ & $\$ 918$ & 9,030 & $\$ 3,775$ & $\$ 6,432$ & $\$ 10,910$ \\
\hline West North Central & 2,464 & $\$ 78$ & $\$ 428$ & $\$ 743$ & 528 & $\$ 5,503$ & $\$ 8,462$ & $\$ 11,072$ \\
\hline West South Central & $|7,36|$ & $\$ 423$ & $\$ 746$ & $\$ 1,676$ & 5,916 & $\$ 3,554$ & $\$ 5,820$ & $\$ 8,609$ \\
\hline Overall & 160,901 & $\$ 255$ & $\$ 532$ & $\$ 931$ & 32,413 & $\$ 4,114$ & $\$ 6,853$ & $\$ 10,528$ \\
\hline \multicolumn{9}{|l|}{ Payment } \\
\hline East North Central & 22,069 & $\$ 152$ & $\$ 506$ & $\$ 1,289$ & 3,673 & $\$ 5,835$ & $\$ 10,105$ & $\$ 21,617$ \\
\hline East South Central & 10,438 & $\$ 465$ & $\$ 839$ & $\$ 1,154$ & 2,866 & $\$ 3,644$ & $\$ 4,78$ I & $\$ 5,867$ \\
\hline Mid-Atlantic & 22,191 & $\$ 120$ & $\$ 313$ & $\$ 558$ & 3,708 & $\$ 5,997$ & $\$ 9,284$ & $\$ 14,430$ \\
\hline Mountain & 4,292 & $\$ 186$ & $\$ 538$ & $\$ 1,064$ & 613 & $\$ 7,145$ & $\$ 12,062$ & $\$ 21,070$ \\
\hline New England & 18,407 & $\$ 289$ & $\$ 380$ & $\$ 648$ & 933 & $\$ 7,685$ & $\$ 9,668$ & $\$ 9,833$ \\
\hline Pacific & 25,426 & $\$ 322$ & $\$ 1,012$ & $\$ 1,988$ & 5,146 & $\$ 7,575$ & $\$ 10,701$ & $\$ 15,849$ \\
\hline South Atlantic & 38,253 & $\$ 245$ & $\$ 691$ & $\$ 1,322$ & 9,030 & $\$ 5,250$ & $\$ 7,829$ & $\$ 12,588$ \\
\hline West North Central & 2,464 & $\$ 498$ & $\$ 815$ & $\$ 1,053$ & 528 & $\$ 6,145$ & $\$ 7,567$ & $\$ 6,933$ \\
\hline West South Central & $|7,36|$ & $\$ 254$ & $\$ 747$ & $\$ 1,920$ & 5,916 & $\$ 5,704$ & $\$ 7,788$ & $\$ 12,484$ \\
\hline Overall & 160,901 & $\$ 220$ & $\$ 585$ & $\$ 1,353$ & 32,413 & $\$ 6,114$ & $\$ 8,731$ & $\$ 14,069$ \\
\hline \multicolumn{9}{|l|}{ LOS } \\
\hline East North Central & & & & & 3,673 & 4.0 & 4.3 & 3.3 \\
\hline East South Central & & & & & 2,866 & 5.0 & 5.2 & 3.8 \\
\hline Mid-Atlantic & & & & & 3,708 & 5.0 & 7.1 & 6.8 \\
\hline Mountain & & & & & 613 & 4.0 & 5.0 & 4.1 \\
\hline New England & & & & & 933 & 4.0 & 5.2 & 5.6 \\
\hline Pacific & & & & & 5,146 & 5.0 & 6.2 & 5.6 \\
\hline South Atlantic & & & & & 9,030 & 4.0 & 5.3 & 5.8 \\
\hline West North Central & & & & & 528 & 3.0 & 4.6 & 4.5 \\
\hline West South Central & & & & & 5,916 & 4.0 & 5.2 & 4.3 \\
\hline Overall & & & & & 32,413 & 4.0 & 5.5 & 5.2 \\
\hline
\end{tabular}

Abbreviation: LOS, length of stay.

Journal of Pain Research

\section{Publish your work in this journal}

The Journal of Pain Research is an international, peer reviewed, open access, online journal that welcomes laboratory and clinical findings in the fields of pain research and the prevention and management of pain. Original research, reviews, symposium reports, hypothesis formation and commentaries are all considered for publication.
The manuscript management system is completely online and includes a very quick and fair peer-review system, which is all easy to use. Visit http://www.dovepress.com/testimonials.php to read real quotes from published authors. 